\title{
Toxicological investigations on silicon carbide. 1. Inhalation studies
}

\author{
J Bruch, B Rehn, H Song, E Gono, W Malkusch
}

\begin{abstract}
The question of lung damage as a result of exposure to silicon carbide (SiC) was investigated by inhalation experiments to obtain information on the qualitative response of lung tissue to the test substance (SiC). For comparison, quartz, kaolinite, and tempered clay dusts were used. The indices for the effects of the dusts studied were organ weights, numbers of bronchoalveolar cells, lung surfactant phospholipid concentrations including subfractions, and lung clearance. Exposure to the test samples was carried out according to the Essen inhalation model in two independent series. The results of the two series were similar: Compared with sham controls, exposure to $\mathrm{SiC}$ did not affect the indices studied. Even at a low dose (a quarter of the SiC dose) quartz gave pronounced deviations in all indices. In particular, an increase in granulocytes indicated toxic properties of the dust. The long term elimination of quartz from the lung was worse than that of SiC. The kaolinite and tempered clay dusts were intermediate between SiC and quartz based on several of the indices studied. It is concluded that $\mathrm{SiC}$ is deposited practically inert in the lung.
\end{abstract}

(British fournal of Industrial Medicine 1993;50:797-806)

Old occupational studies showed that employees involved with synthetic abrasives had an up to twofold increase in the incidence of tuberculosis. This was considered to be the result of a silicogenic effect. On the other hand, it was also shown that such workers developed significantly less fibroses than those working with sandstone. ${ }^{1}$

Institute for Hygiene and Occupational Medicine, University of Essen, Medical School (Universitätsklinikum), Hufelandstrasse 55, 4300 Essen 1, Germany

J Bruch, B Rehn, H Song, E Gono, W Malkusch
In a more recent epidemiological study based on medical examinations and lung radiographs, no increase in lung disease was found in workers that used synthetic abrasives in conjunction with premanufactured silicon carbide (SiC) abrasive wheels. There was, however, a limited pneumoconiosis hazard in those concerned with $\mathrm{SiC}$ production. ${ }^{2}$

Only few reports are available on the causes. Open lung biopsies from two employees working for a fireproof brick manufacturing plant found substantial amounts of $\mathrm{SiC}$ and other dusts but not quartz. ${ }^{3}$ An interstitial fibrosis in lung tissue was diagnosed in a further case after only a one year exposure to various non-quartz abrasive dusts. As the patient was a heavy smoker and also subjected to other inhalative noxious compounds in his earlier working life, this could not be unequivocally related to the abrasive dusts.

Significant increases in pulmonary diseases have also been reported by $\mathrm{SiC}$ manufacturing plants. In the most comprehensive study to date, 171 men from $\mathrm{SiC}$ industrial manufacturing branches were examined radiologically and by means of lung function tests; $35 \%$ of workers showed shadows on the radiographs with average profusion greater than $0 / 1$ and $14 \%$ had average profusion readings of greater than $1 / 1$. In this report the highest quartz concentration amounted to $0.1 \mathrm{mg} / \mathrm{m}^{3}$ whereas that of $\mathrm{SiC}$ was $0.57 \mathrm{mg} / \mathrm{m}^{3}{ }^{4}$ Exposures to quartz and other crystalline $\mathrm{SiO}_{2}$ compounds in the manufacturing plants must be taken into account as competing causes; according to our findings these can be present in significantly greater concentrations than the mentioned values for $\mathrm{SiC}$ and quartz. ${ }^{56}$ Moreover, manufacture related exposures to $\mathrm{SiO}_{2}$ also exist. ${ }^{7}$ The recent study by Durand et $a l^{8}$ concerning alterations in chest radiographs was based on a cohort of 128 workers exposed to $\mathrm{SiC}$ in a manufacturing plant. The authors reported that the workers were exposed to crystalline $\mathrm{SiO}_{2}$ during various manufacturing stages. Also, $\mathrm{SiC}$ fibres were present in the respired air. Both must be considered to be confounders during exposure to $\mathrm{SiC}$ dust.

The results from animal experiments are contradictory: older studies with ill defined experimental 
conditions have reported fibrogenic effects. ${ }^{1}$ Another group has reported negative results in animal experiments and concluded that $\mathrm{SiC}$ dust is inert. ${ }^{9}$

After an inquiry, the commission for establishing threshold values for dusts of the Deutsche Forschungsgemeinschaft (DFG) concerned itself with the setting up of hygiene standards for $\mathrm{SiC}$ in 1985. After assessing the available experimental animal and epidemiological findings, a fibrogenic effect could not be absolutely ruled out and a threshold value for $\mathrm{SiC}$ was introduced as a precautionary measure.

As accompanying quartz admixtures could not be excluded with certainty in the considerations when establishing the threshold value, the question of pneumoconiotic effects of $\mathrm{SiC}$ need to be checked in animal studies taking more recent inhalatory toxicological procedures into account. According to general medical opinion, pneumoconioses are pulmonary diseases caused by dusts and are characterised by chronic inflammatory alterations to the lung tissue with scarring of the organ structure. Clinical symptoms such as shortness of breath and tightness of the chest are found; in general, it is assumed that there is a progression of the disease after sufficient exposure. The pathogenesis of pneumoconioses can be attributed simplistically to an inflammatory stimulation of alveolar macrophages. This stimulation of cells responsible for defence and removal gives rise to several harmful sequelae-namely, (1) worsening of lung clearance, normally between about 97 and $99 \%^{1011}$; (2) scarring of lung tissue as a result of the chronic intra-alveolar inflammation ${ }^{12}$; (3) disintegration of the respiring lung tissue with consecutive emphyse$\mathrm{ma}^{13}$; (4) response of the pneumocyte type II surfactant system with deterioration of lung function. In this case, specific reactions of a lung epithelial cell type to silica are involved. ${ }^{14-16}$ To check for pathogenesis of pneumoconioses, animal studies should test both the acute intra-alveolar processes as well as the chronic effects of dusts on pulmonary health. For methodological reasons, the experiments should be carried out after inhalation of the test substances to determine the intra-alveolar mechanisms involved. The often used method of intratracheal injection interferes with the sensitive primary pulmonary defence system due to the rough method of application so that subsequent effects may not be testable. By contrast the chronic effects can be examined by giving a sufficiently high dose via intratracheal injection and assuming the worst case after a sufficiently long dust exposure time (usually between six and 12 months). This paper deals with the inhalation studies. Experiments with the intratracheal application of $\mathrm{SiC}$ are reported in a companion paper. ${ }^{17}$

\section{Materials and methods}

DUST SAMPLES

The dust samples under study were $\mathrm{SiC}$ (Wacker GmbH batch No D Mikro-F1200 M678), corundum (fused alumina; Wacker $\mathrm{GmbH}$ batch No D F1200/3 M74375), kaolinite, tempered and ground clay, and quartz (DQ12, DMT, Essen). The average grain size was below $3 \mu \mathrm{m}$.

ANIMALS AND EXPOSURE SCHEMES: STUDY DESIGN Female Wistar rats, initial body weight, $180-220 \mathrm{~g}$ (Lippische Versuchstierzucht, Charles River Co) were used. The rats were exposed oronasally in a modified Kimmerle inhalation chamber. Conditions in the chamber were in accordance with the Organisation for Economic Cooperation and Development guidelines for testing of chemicals. Dust concentration was measured gravimetrically with a Cassella instrument Johannesburg Convention for Fine Dusts) and monitored continuously by a Tyndallometer (Hundt- $\mu$ Digital, Wetzlar, Germany).

The animals were exposed for five hours a day on five consecutive days, followed by a rest period of two days and a re-exposure period of five consecutive days. Total exposure time was $\mathbf{5 0}$ hours. The inhalation schedules, including two sets of independent inhalation series; were:

First inhalation series (50 animals in each group)

(1) Exposure to a constant concentration of $20 \mathrm{mg}$ $\mathrm{SiC} / \mathrm{m}^{3}$ respirable air for five hours a day.

(2) Exposure to a constant concentration of $20 \mathrm{mg}$ quartz/ $\mathrm{m}^{3}$ respirable air for one hour a day followed by an exposure of $20 \mathrm{mg} \mathrm{SiC} / \mathrm{m}^{3}$ respirable air for four hours a day.

(3) Exposure to a constant concentration of $20 \mathrm{mg}$ kaolinite $/ \mathrm{m}^{3}$ respirable air for one hour a day followed by an exposure of $20 \mathrm{mg} \mathrm{SiC} / \mathrm{m}^{3}$ respirable air for four hours a day.

(4) Exposure to a constant concentration of $20 \mathrm{mg}$ corundum $/ \mathrm{m}^{3}$ respirable air for five hours a day (15 animals).

Second inhalation series (42 in animals each group)

(1) Exposure to a constant concentration of $20 \mathrm{mg}$ $\mathrm{SiC} / \mathrm{m}^{3}$ respirable air for five hours a day.

(2) Exposure to a constant concentration of $20 \mathrm{mg}$ quartz/ $\mathrm{m}^{3}$ respirable air for five hours a day.

(3) Exposure to a constant concentration of $20 \mathrm{mg}$ tempered, ground clay dust $/ \mathrm{m}^{3}$ respirable air for five hours a day.

(4) Sham exposure (to air).

\section{INVESTIGATION OF BRONCHOALVEOLAR LAVAGE}

FLUID

Three and 90 days after exposure in the first series, and three, 21, and 90 days after exposure in the 

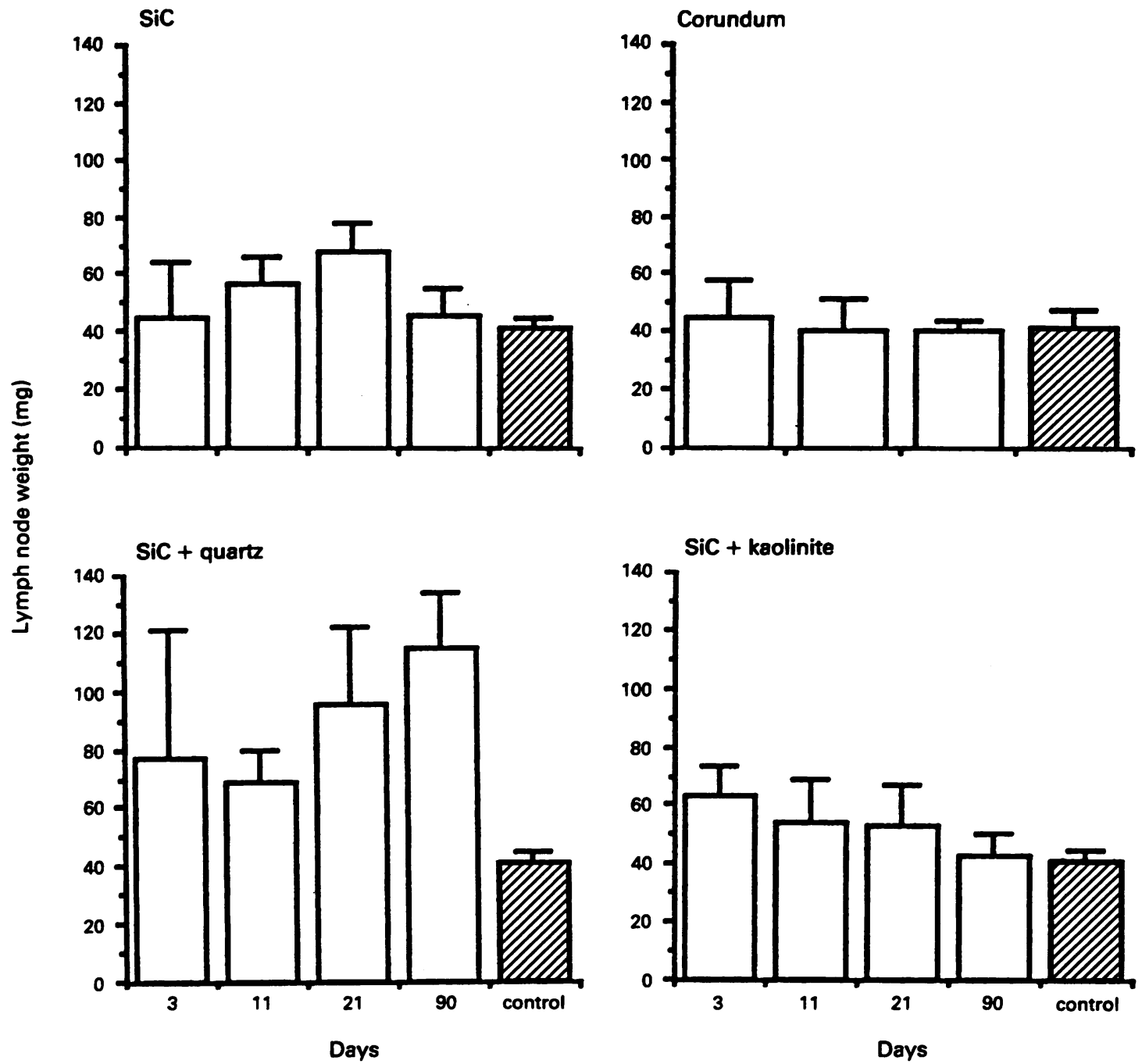

Time of investigation

Figure 1 First inhalation series; comparison of wet weights of mediastinal lymph nodes. Values are mean (SD) from eight animals per group per investigation date. A significant increase in weight until the end of the investigation occurred only in the $\mathrm{SiC}+$ quartz group.

second inhalation series, seven rats per group and seven control rats exposed to air were killed with an overdose of pentobarbital and exsanguinated; the trachea was cannulated, and the lungs were degassed and lavaged in situ five times through the trachea, each time with $5 \mathrm{ml}$ physiological saline. The lavage fluid was centrifuged $(300 \mathrm{~g}$ for $10 \mathrm{~min}$ utes at $4^{\circ} \mathrm{C}$ ) to sediment the cells. The cells were resuspended in Hanks balanced salt solution and total cell counts were made with a cell counter (Coulter Electronics). Differential cell counts were made from cytocentrifuge smears treated with Pappenheim stain.
Lung surfactant factor (LSF) phospholipids were extracted by the method of Folch et al (1957). Supernatant lavage fluid $(10 \mathrm{ml})$ was added to 30 $\mathrm{ml}$ chloroform:methanol (2:1) and the mixture was stirred for five minutes and centrifuged $(1100 \mathrm{~g}$ for 5 minutes at $4^{\circ} \mathrm{C}$ ) to separate the methanol and chloroform layers. The chloroform layer was removed, dried under nitrogen, and redissolved in $200 \mu \mathrm{l}$ chloroform:methanol (2:1) for analysis by high performance liquid chromatography (HPLC). The LSF phospholipids were separated according to the method of Pison et al. ${ }^{18}$ The equipment (pump with gradient former, spectrophotometer, 
and computing software) was purchased from Gynotek (Munich, Germany). The chromatographic analysis was performed at $30^{\circ} \mathrm{C}$ at a flow rate of $2 \mathrm{ml} / \mathrm{min}$ on a column $(250 \times 4 \mathrm{~mm}$ internal diameter) prepacked with Lichrosorb diol $(5 \mu \mathrm{m})$. A guard column $(75 \times 4.6 \mathrm{~mm}$ internal diameter $)$ was prepacked with Si $100(30 \mu \mathrm{m})$ (Serva). The mobile phase consisted of acetonitrile:water (80:20; $\mathrm{pH} \mathrm{6)}$ and pure acetonitrile. A linear gradient from $87.5 \%$ to $25 \%$ for pure acetonitrile was formed between six and 15 minutes. Detection wavelength was set at $200 \mathrm{~nm}$. Phospholipid composition was calculated by comparison with standard phospholipid mixtures (phosphatidyl glycerol (PG), phosphatidyl inositol, (PI), phosphatidyl ethanolamine, phosphatidyl choline, lysophosphatidyl choline, and sphingomyelin) obtained from Sigma, Munich, Germany.

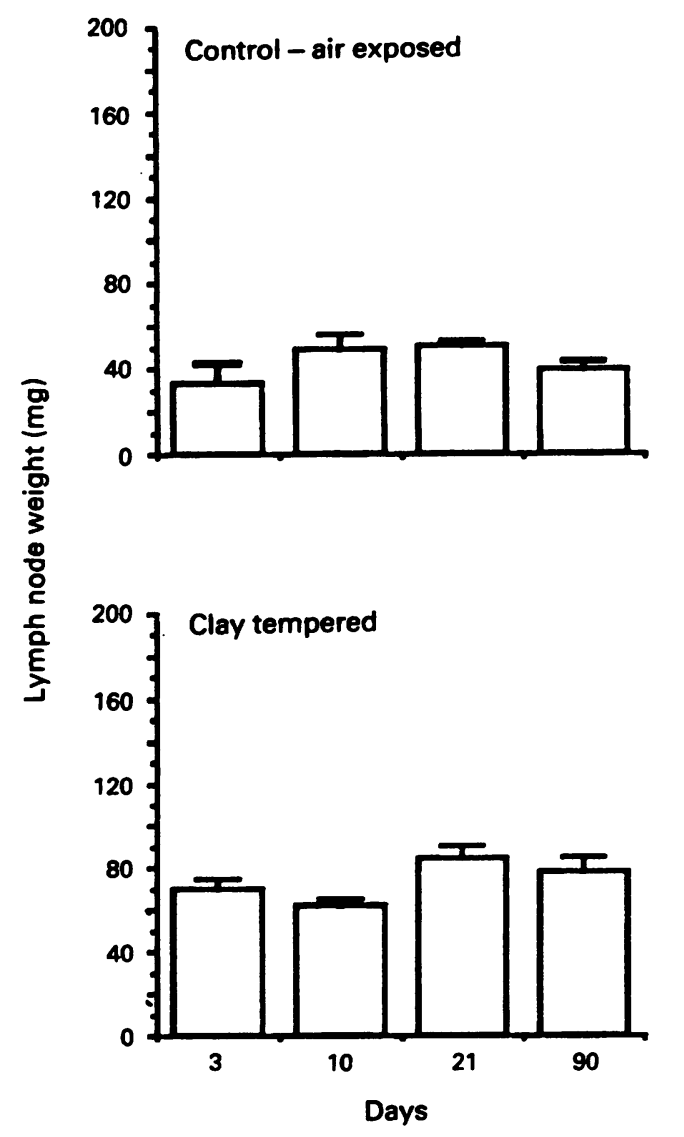

\section{LUNG FUNCTION}

A lung function test was carried on eight animals of the first inhalation series, which included exposure to $\mathrm{SiC}$, kaolinite, quartz, and corundum. Eight lungs of each exposure group were excised 90 days after finishing the inhalation and tested for peak flow.

\section{ELIMINATION OF DUST FROM THE LUNGS}

Seven rats per group were killed with an overdose of pentobarbital $3,11,21$, and 90 days after exposure in the first inhalation series, and 3, 21, and 90 days after exposure in the second series. The lungs were removed and stored in acetone for measuring the dust content in the tissue. Dust content was determined gravimetrically with a formic acid digestion method.
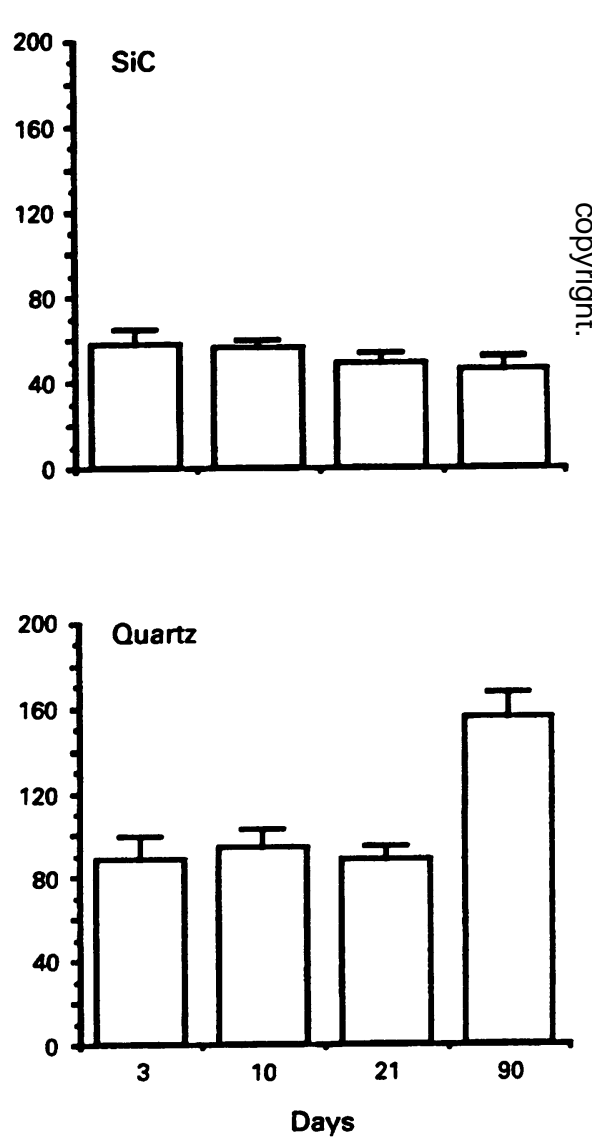

Time of investigation

Figure 2 Second inhalation series; comparison of wet weights of mediastinal lymph nodes. Values are mean (SD) from eight animals per group per investigation date. A significant increase in weight until the end of the investigation occurred only in the quartz group. 

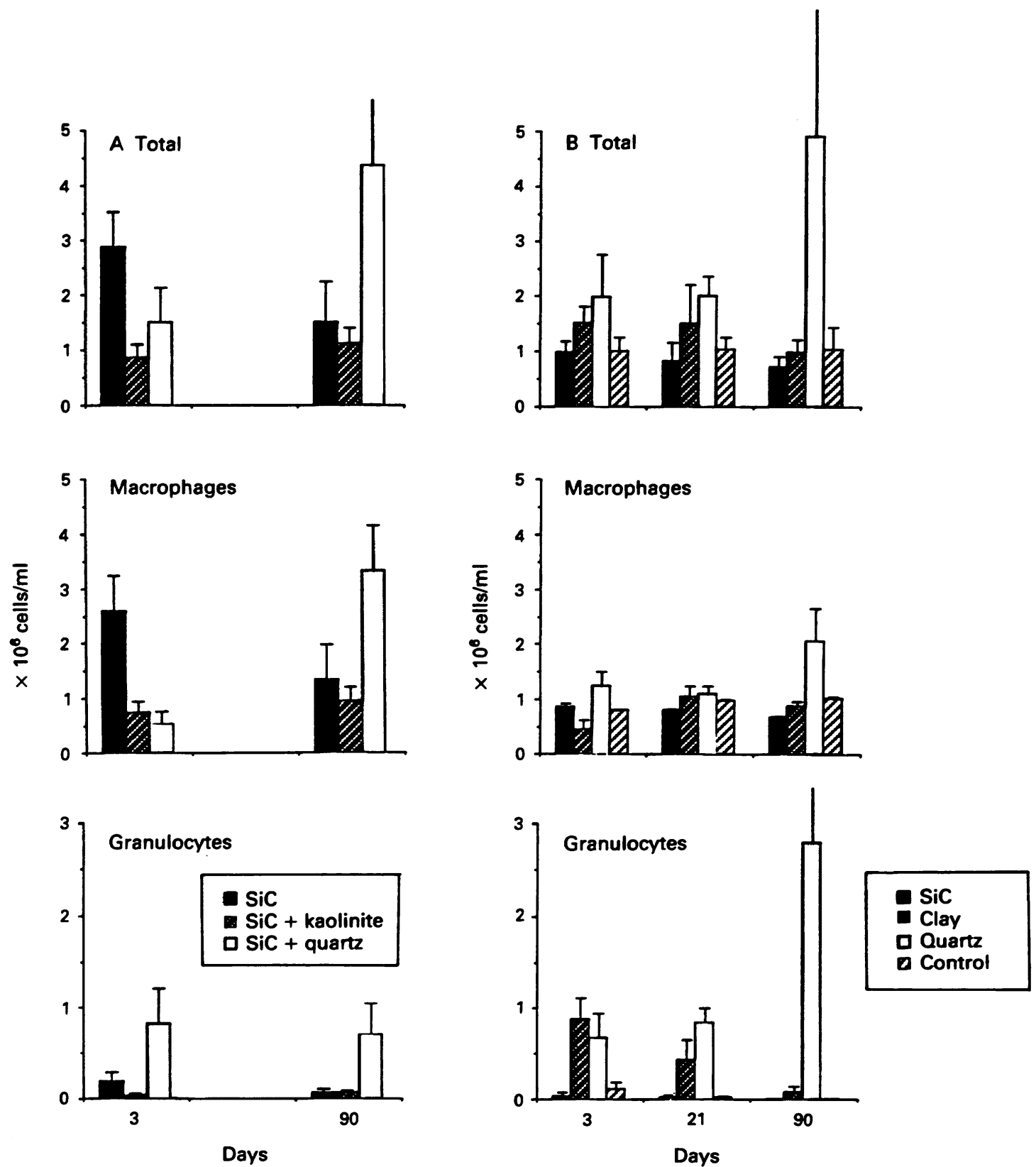

Figure 3 Mean (SD) total number of cells, macrophages, and granulocytes in BAL fluid from (A) first inhalation series, (B) second inhalation series. Significantly increased numbers of granulocytes occurred in animals exposed to quartz (both series) and clay (days 3 and 21 , second series).

\section{Results}

ORGAN WEIGHTS AND HISTOLOGY

In both inhalation series, the rats showed normal behaviour and normal development after the inhalation and during the observation period of 90 days.
In the first series a comparison of weight development of the mediastinal lymph nodes showed no significant deviations from normal after exposure to $\mathrm{SiC}$ or corundum (fig 1). Additional exposure to quartz resulted in a significant weight increase in the lymph nodes as an expression of the pathogenic 

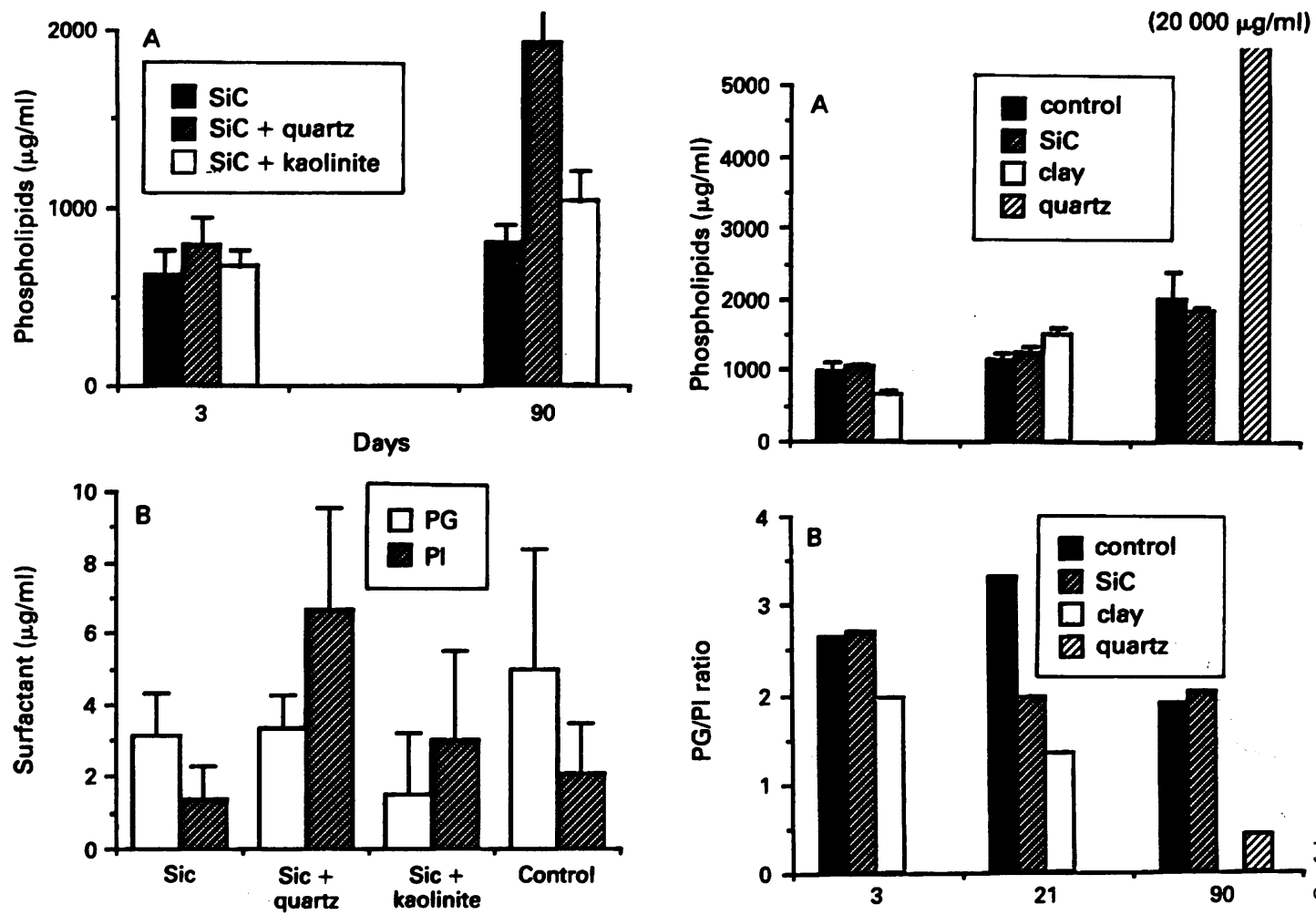

Figure 4 (A) Total phospholipids (mean SD) in the first inhalation series. Concentration was significantly increased at 90 days in the quartz group. (B) Ratio of LSF subfractions at day 90 after exposure. Ratio PG:PI is roughly 2:1 for control and $\mathrm{SiC}$ groups and 1:2 for $\mathrm{SiC}+$ quartz and $\mathrm{SiC}+$ kaolinite groups.

response of the lymphatic tissue.

The second series involved a group of eight animals subjected to $\mathrm{SiC}$ inhalation at a concentration of $20 \mathrm{mg} / \mathrm{m}^{3}$, as in the first series. Quartz DQ12 served as a positive control dust but, contrary to the first series, this was applied at a dose of $20 \mathrm{mg} / \mathrm{m}^{3}$ for five hours daily on $2 \times 5$ days as was a clay dust (tempered, ground) also given at a concentration of $20 \mathrm{mg} / \mathrm{m}^{3}$. All animals exposed to dust showed increased lymph node weights; however, the weights for the quartz group were clearly greater than those for the SiC and clay dust groups as early as day 3 after ending inhalation (fig 2).

None of the groups showed any significant changes in lung weights compared with the controls.

\section{CELLS IN BRONCHOALVEOLAR LAVAGE FLUID}

In the first series bronchoalveolar lavages (BALs) permitted conclusions to be drawn about the intraalveolar processes prevailing at the time of investi-

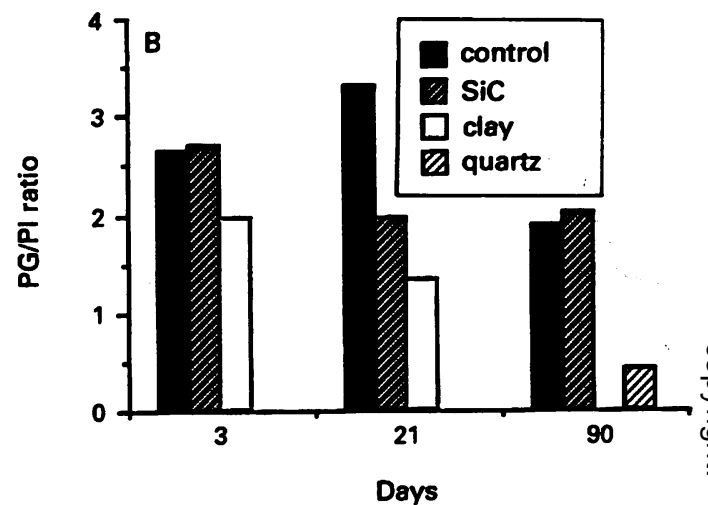

Figure 5 (A) Total phospholipids (mean (SD)) in the second inhalation series. Concentration was significantly increased at 90 days in the quartz group. (B) Ratio of LSF subfractions at day 90 after exposure. All PG:PI ratios above 1.5 except for quartz group at day $90(<0.5)$.

gation. Of interest in the present study are the results of the cell numbers and the involvement of various cell types in the pulmonary response to the effects of dust. High total cell numbers as well as alveolar macrophages were found three days after the end of inhalation in the $\mathrm{SiC}$ group (fig 3A). These conditions were reversed after 90 days, when increased cell numbers were found in the quartz treated group. These values must be regarded as the result of an adaptive adjustment to dust exposure in association with the toxic effects of the individual samples. The number of granulocytes reflects the pathological inflammatory stimulus. The results in fig 3A show a strong inflammatory stimulation by quartz dusts, whereas $\mathrm{SiC}$ and kaolinite apparently produce no specific stimulation of granulocytes.

Similar results were found in the second series of studies. Here, a sham control was used. The number of cells in lavage fluid was similar in the sham control and $\mathrm{SiC}$ group over the entire experimental 


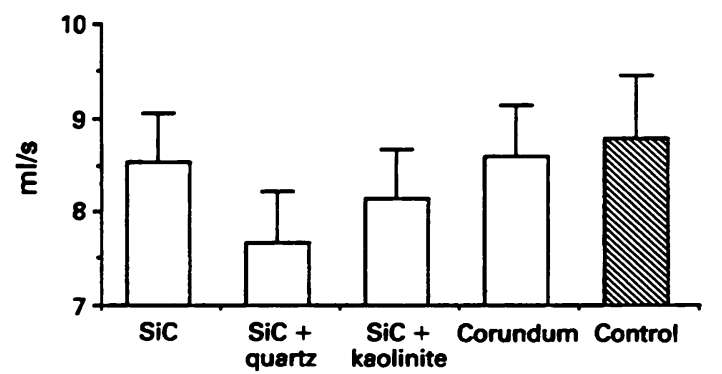

Figure 6 Maximum peak flow (mean (SD) values at 90 days after exposure). Values for $\mathrm{SiC}+$ quartz and $\mathrm{SiC}+$ kaolinite groups were significantly lower than controls.

period (fig 3B). More cells were found in the BAL fluid of groups exposed to clay and quartz. The numbers in animals exposed to clay mineral were normal by day 90 .

Exposure to $\mathrm{SiC}$ did not result in a noticeable shift in the numbers of alveolar macrophages, lymphocytes, and granulocytes in the total cell number. Figure 3B shows that the number of lymphocytes and granulocytes constitute less than $10 \%$ of the total cell number.

The situation was different in the case of quartz. As the dust concentration was fivefold higher compared with the first series, a correspondingly higher granulocytic response was seen in the BAL fluid. The findings indicate that at this concentration there was an increase in the amounts of granulocytes even up to day 90 of observation. Up to $70 \%$ of cells found in the lungs were granulocytes.

\section{LUNG SURFACTANT PHOSPHOLIPIDS IN \\ BRONCHOALVEOLAR LAVAGE FLUID}

The LSF phospholipids are a component of the pneumocyte type II-LSF system. Both the total amount of LSF phospholipids as well as the composition of the subfractions need to be considered. Pronounced responses are to be expected based on clinical and experimental studies of intra-alveolar inflammatory processes, particularly in the case of initiation of fibrotic processes of different origin.

In both series the total amount of LSF phospholipids was only increased in animals exposed to quartz (figs $4 \mathrm{~A}$ and $5 \mathrm{~A}$ ).

The relation between subfractions of LSF is a particularly sensitive response to the inflammatory or fibrogenic effects of dusts. In particular the relation between PG and PI reflects the changes in the intra-alveolar environment. According to earlier studies, the normal ratios range from $2: 1$ to $3: 1$. On exposure to quartz and kaolinite abnormal ratios of $\leqslant 1: 1$ were obtained. By contrast, $\mathrm{SiC}$ induced no such alterations in the LSF subfractions, with values corresponding to those of the untreated control animals (fig 4B). In the second series of studies, there were indications of a slight but significant decrease below the level of 2:1 after exposure to clay as well as a slight toxic effect at day 21 after inhalation (fig 5B). This finding is in agreement with the increase in granulocytes in the BAL fluid also seen at this time.

\section{LUNG FUNCTION}

Figure 6 presents the results of the testing of the five exposure groups. Control animals as well as animals exposed to $\mathrm{SiC}$ showed simular maximum flow values $(>8.5 \mathrm{ml} / \mathrm{s}$ ), whereas exposure to quartz and to a lesser degree kaolinite gave lower flow rates $(<8.0 \mathrm{ml} / \mathrm{s})$.

\section{ELIMINATION OF DUST FROM THE LUNG}

Elimination studies show a differential response to $\mathrm{SiC}$ and quartz. Two inhalation series with $\mathrm{SiC}$ were carried out: $\mathrm{SiC}$ alone and quartz in combination with $\mathrm{SiC}$ (first series) as well as $\mathrm{SiC}$ alone compared with quartz alone (second series). Both
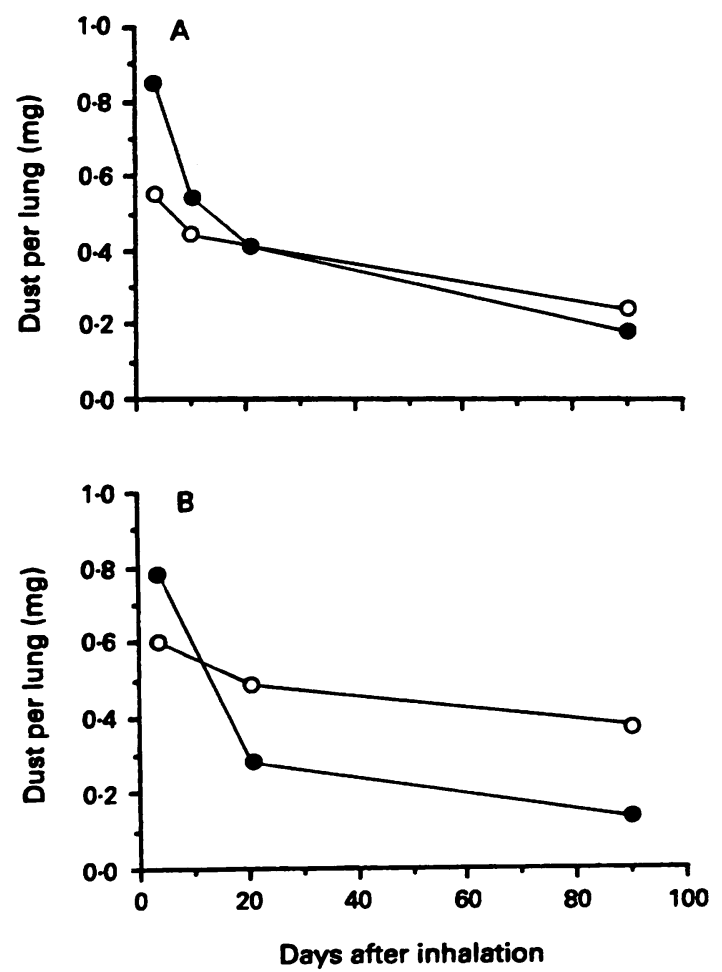

Figure 7 Dust deposits in lungs. (A) first inhalation series (@ SiC, OSiC + quartz); (B) second inhalation series ( $S i C$, O quartz). Dust deposits at day 3 after inhalation were higher in $\mathrm{SiC}$ group. Subsequently $\mathrm{SiC}$ was eliminated more effectively. 
inhalation series produced similar results (fig 7A and B). The initial amount of dust directly determined on day 3 showed the lowest and highest lung dust burden in the groups exposed to quartz and $\mathrm{SiC}$ alone respectively. The experimental times of investigation allowed the elimination rate to be determined from these different starting points. Quartz elimination was clearly inhibited up to 90 days after completion of elimination. In the case of $\mathrm{SiC}$ only $23 \%$ of the initial amount was found in the lungs, but $60 \%$ of quartz was still retained. In our opinion, the differing situation at day 3 is due to an initially enhanced elimination during exposure to quartz dust; clear evidence of this was obtained from previous studies. On the other hand, the present data cannot definitely rule out that a different primary deposition based on non-uniform grain size distribution had taken place.

\section{Discussion}

The toxicological studies on the biological effects of $\mathrm{SiC}$ were carried out with the aid of inhalation experiments. The standard reference dust quartz DQ12 and corundum served as comparative dusts together with various clay mineral dusts. The inhalation experiments were carried out according to the standard model in Essen, which allows the investigation of both the initial inflammatory processes in the alveoli (alveolitis) directly after dust exposure (three days postinhalation) and possible long term pulmonary damage (21-90 days postinhalation). Based on other studies it is known that distinct fibrotic responses can be detected in the lungs and in the mediastinal lymph nodes even with colliery dusts containing less than $1 \%$ of quartz at the doses used in the same experimental design. ${ }^{19}$ In these studies, however, less emphasis was placed on the question as to what extent the dusts studied caused chronic pulmonary diseases and more on the testing of decisive primary events after dust deposition which contribute to the type and extent of fibrogenic pneumoniotic diseases. These events are primarily associated with the alveoli and result from the effects arising from the interaction between alveolar macrophages and dust. These effects include the liberation of mediators, to cause inflammatory processes as well as stimulation of the lung surfactant pneumocyte type II system. The indirect effects of these primary actions are alterations to clearance efficiency of the lungs and an enhanced lung dust burden. This results in the decisive lung dust dose that, in conjunction with the specific fibroblastic effects of the particles, is finally responsible for the overall effect of the dusts.

To prevent non-specific side effects by unphysiological dust application-for instance, intratracheal instillation-inhalation experiments have been used. Thus the qualitative onset of the questionable pathogenic event chain induced by the test substances can be investigated. Non-specific epiphenomena by intratracheal injection are possibly inflammation to dust overload and a non-specific outcome to lung elimination and dust retention.

Valuable information can be obtained from the results of inhalation experiments. These are designed to test the acute effects of dust as well as to study those events leading to chronic and terminal transition of dust effects. Initially, organ weights can be used as the simplest variable and those of the mediastinal lymph nodes are of particular value in the case of fibrogenic and cytopathogenic dusts. These simple variables reflect the three divisional toxicity of dusts in the samples studied. Roughly the dusts can be subdivided into three classes:

(1) Dusts without recognisable effects in relation to air controls-namely, $\mathrm{SiC}$, corundum, and kaolinite in one experiment.

(2) Dusts with small and only transitory effectsnamely, tempered clay as well as low doses of the positive reference dust, quartz DQ12.

(3) The toxic quartz DQ12, which produced effects in all variables studied at the standard dose.

Quartz showed the highest effects whereby the weight of the lungs and also the lymph nodes had increased soon after ending inhalation. There was also a progressive increase over the entire observa-ê tion period of 90 days. The dusts of intermediate? toxicity-for example, kaolinite colliery dust-only gave a temporary increase in lymph node weights. By contrast, $\mathrm{SiC}$ produced no significant changes in organ weights at any time of observation.

Further variables were cell populations determined from the BAL fluid, analysed for cell number and composition. Normally, about $90 \%$ of cells in BAL fluid are alveolar macrophages and the remainder are made up of lymphocytes and a few granulocytes. The number of macrophages increases on exposure to toxic dusts, a certain amount of which is attributable to socalled inert dusts resulting in a physiological response. The amount of granulocytes in BAL fluid is a sensitive index of possible toxic dust effects. ${ }^{20-24}$ In principle, the present data show three response patterns: firstly, no reactions, secondly, a transient increase in granulocytes and a decrease in the period between the 21 st and the 90th day after inhalation, and thirdly a definitive increase and steady state at a high level even at day 90 after completing inhalation. The granulocytes precisely reflect the situations already found in in vitro tests, which, on the one hand, allow $\mathrm{SiC}$ to be classified as the least stimulatory dust and, on the other, quartz as the most stimulatory. The other samples studied characteristically only showed a transient increase in the amount of granulocytes in the BAL fluid directly after inhala- 
tion. An important activity of alveolar macrophages is that of scavenger function. Lung purging was clearly affected within the limits of the test model; thus an initial phase of lung purging seems to be stimulated by toxic dusts. This is in agreement with the results from other investigations on colliery dusts. ${ }^{25} 26$ After 90 days, these circumstances were reversed, because $\mathrm{SiC}$ is much better eliminated than the toxic dust at this time. This continuous progressive improved elimination must be ranked as favourable in terms of health assessment.

Valuable information can be derived from the results on lung surfactant. Here, a distinct gradation of the effects between the unexposed controls and quartz treated animals was registered. The amount of surfactant is an important index. Quartz gave a pronounced and lasting increase in surfactant; this agrees with the results of many other experiments on silica. 14162728 The cause of the excessive surfactant production by silica is due to the pathogenic stimulation of the type II pneumocytes by factors released from the alveolar macrophages. ${ }^{15} \mathrm{~A}$ corresponding increase was not found with the control dusts (clay mineral dusts, kaolinite) or with $\mathrm{SiC}$. In our opinion composition of LSF subfractions provides a sensitive, graduated indication of minor effects from dusts not able to be detected by other variables. ${ }^{29} 30$ In this case, the absolute amounts of PG and PI as well as the relation between the two substances have proved to be particularly sensitive indices. Figure 4B shows that $\mathrm{SiC}$ responds similarly to the control both with respect to the total amount as well as the relation of PG to PI. The situation is different with quartz as well as kaolinite where the relation of PG to PI is altered. In other experiments the inversion of the ratio PG:PI has also been found with silica and other substances that induce lung fibrosis. ${ }^{31} 32$ Our results indicate that this ratio is sensitive to subtle changes in intra-alveolar physiology. Worsening of lung function after quartz and kaolinite exposure can be related to the changes in composition of LSF; our results are comparable with those after bleomycin induced pulmonary fibrosis. ${ }^{33}$

An assessment of the changes in relation to primary elimination remains an open question, because according to our clinical experience, this may possibly be considered as a physiological curative response to burdensome situations in the lung. In general the role of surfactant in the context of fibrotic lung diseases is not well understood. There are also clinical data showing that an increase in the amount of surfactant in the BAL fluid is associated with diffuse interstitial fibrosis after exposure to asbestos. ${ }^{34}$ Disturbances in fractional composition are reported from patients with acute respiratory distress syndrome $e^{35}$ and idiopathic pulmonary fibrosis. ${ }^{36}$ The present results on the effect of the dust on the primary phase of elimination are not conclusive. The low lung dust values at day 3 after inhalation of quartz dust can, on the one hand, be caused by a lower primary penetration and deposition or, on the other, by an already increased elimination stimulated during inhalation. The results from particle size distribution seem to support this, as the quartz DQ 12 penetrates rat lung to a higher degree than $\mathrm{SiC}$ dust based on their finer grain size distribution. From this it can be inferred that the primary elimination is initially increased through the general stimulation processes in the alveoli with a greatly enhanced cell recruitment. These results are in agreement with our own studies on mixed dusts, in which dusts of varying cytotoxicity from various areas of work in the colliery were tested and compared with respect to their elimination. Here too a strongly enhanced primary elimination on the part of the more cytotoxic dusts was seen, both during inhalation itself as well as up to 10 days after.

By contrast, the results for long term deposition are clear as can be seen from the data for 90 days after inhalation. Thus cytotoxic quartz led to a distinct long term worsening of elimination compared with $\mathrm{SiC}$. This is in agreement with other results where experiments were designed to study such a long term effect; an increased retention was always noticed in the case of cytotoxic quartz compared with other dusts studied. The causes of the increased retention lie in the enhanced transition rate of the quartz dust into the intraseptal and lymphatic regions of the lung. This agrees with the fact that after inhalation of quartz dust the lymph node weights were noticeably increased in comparison with those seen with other dusts (lymphotropism of quartz dusts according to Klosterkötter). It is remarkable that as well as the high elimination of $\mathrm{SiC}$ practically no lymphatic penetration by the dust had taken place. From a hygienic point of view, it is relevant that even this index shows no negative response under the influence of $\mathrm{SiC}$. It can be concluded that a burdensome situation necessitating a physiological curative response is not given for SiC. The significance of these results in respect to the medical hygienic evaluation for $\mathrm{SiC}$ is discussed in the accompanying paper. ${ }^{17}$

\section{Summary and conclusions}

The hygienic, occupational medical rating of the major test substance $\mathrm{SiC}$ is based on experimental procedures related to primary pulmonary reactions following deposition. The present results were obtained with several independent assays and two different inhalation experiments.

All results obtained were consistent and correspond to the present day knowledge on the initia- 
tion of chronic pneumopathies from events primarily induced in the alveolus. The role of alveolar macrophages in lung purging as well as the sensitive changes in the LSF PII cell system are in agreement with the results of the differential cell pattern in BAL fluid as well as those of TNF- $a$ production from the various exposure situations (see companion paper). ${ }^{17}$

SiC showed no divergent results from those of controls in all the tests studied. By contrast, quartz always behaved differently from the control and $\mathrm{SiC}$ even at small doses. Various other dust samples cotested were considered to be of intermediate toxicity in several indices. Here, the testing of LSF subfractions proved to be particularly sensitive. A final ranking of substances from an occupational medicine-hygienic viewpoint should be undertaken in conjunction with the results from long term studies.

1 Gardner LU. Studies on the relation of mineral dusts to tuberculosis. III. The relatively early lesions in experimental pneumoconiosis produced by carborundum inhalation and their influence on pulmonary tuberculosis. American Review of Tuberculosis 1923;7:344-57.

2 Bruusgaard A. Abrasives. Encyclopaedia of occupational health and safety, 1983;1:4-5.

3 Funahashi A, Schlueter DP, Pintar K, et al. Pneumoconiosis in workers exposed to silicon carbide. Am Rev Respir Dis 1984;129:635-40.

4 Peters JM, Smith TJ, Bernstein L, Wright WE, Hammond SK. Pulmonary effects of exposures in silicon carbide manufacturing. Br F Ind Med 1984;41:109-15.

5 Smith TJ, Hammond SK, Laidlaw F, Fine S. Respiratory exposures associated with silicon carbide production: estimation of cumulative exposures for an epidemiological study. Br $¥$ Ind Med 1984;41:100-8.

6 Bruch J. Personal observation and discussion with hygienic inspection of the ESD Delfzui, Holland: 1989.

7 Osterman JW, Greaves IA, Smith TJ, et al. Respiratory symptoms associated with low level sulphur dioxide exposure in silicon carbide production workers. $\mathrm{Br} \mathcal{F}$ Ind Med 1989; 46:629-35.

8 Durand $\mathrm{P}$, Begin R, Samson L, et al. Silicon carbide pneumoconiosis: a radiographic assessment. Am $\mathcal{F}$ Ind Med 1991; 20:37-47.

9 Miller JW, Sayers RR. The physiological response of peritoneal tissue to certain industrial and pure mineral dusts. Public Health Rep 1936;51:1677-88.

10 Gross $P$. The processes involved in biological aspects of pulmonary deposition, clearence and retention of insoluble aerosols. Health Phys 1964;10:995-1002.

11 Klosterkötter W, Gono $\mathrm{E}$. Long term storage, migration and elimination of dust in the lungs of animals, with special respect to the influence of polyvinyl-pyridine-n-oxide. Oxford: Unwin Brothers, 1971 .

12 Davis GS, Hemenway DR, Evans JN, Lapenas DJ et al. Alveolar macrophage stimulation and population changes in silica-exposed rats. Chest $1981 ; 80: 85-105$.

13 Bruch J, de Beer E, Kraus R, Breining H. Morphometrie menschlicher Silikoselungen. Ergebnisse von Untersuchungen auf dem Gebiet der Staub und Silikosebekämpfung im Steinkohlenbergbau. Steinkohlenbergbauverein (Hrsg) 1989;17: 227-31.

14 Bruch J. Die Vermehrung der Pneumozyten Typ II unter dem Einfluß von Quarz. In: Ergebnisse von Untersuchungen auf dem Gebiet der Staub-und Silikosebekämpfung im Steinkohlebergbau. Essen: 1973: 99-112.

15 Bruch J, Schlösser JW. Veränderung der Zellpopulation in den Alveolen der Rattenlunge nach Inhalation von Quarz und ihre Beeinflussung durch PVNO. In: Ergebnisse von Untersuchungen auf dem Gebiet der Staub-und
Silikosebekämpfung im Steinkohlebergbau. Essen: 1977: 175-84.

16 Miller BE, Dethloff LA, Hook GER. Silica-induced hypertrophy of type II cells in the lungs of rats. Lab Invest 1986;55:153-63.

17 Bruch J, Rehn B, Song W, Gono E, Malkusch W. Toxicological investigations on silicon carbide. 2 In vitro cell tests and long term injection tests. $\mathrm{Br} \mathcal{F}$ Ind Med 1993; 50:807-13.

18 Pison U, Joka T, Obertacke U, Bruch J. Surfactant system and the development of pneumonia during artificial ventilation, 1987 Annual Meeting of the American Thoracic Society, New Orleans. Am Rev Respir Dis 1987;135:A 200.

19 Bruch J, Rehn B. Influence of peak exposure on high and low amount containing mine dust. Luxembourg: $E E C$ research report 1991

20 Donaldson $\mathrm{K}$, Bolton RE, Jones A, et al. Kinetics of the bronchoalveolar leucocyte response in rats during exposure to equal airborne mass concentrations of quartz, chrysotile asbestos, or titanium dioxide. Thorax 1988;43:525-33.

21 Donaldson K, Brown GM. Assessment of mineral dust cytotoxicity toward rat alveolar macrophages using a ${ }^{51} \mathrm{Cr}$ release assay. Fundam Appl Toxicol 1988;10:365-6.

22 Donaldson K, Slight J, Brown GM, Bolton RE. The ability of inflammatory bronchoalveolar leucocyte populations elicited with microbes or mineral dust to injure alveolar epithelial cells and degrade extracellular matrix in vitro. British fournal of Experimental Pathology 1988;69:327-38.

23 Beck BD, Feldman HA, Brain JD, et al. The pulmonary toxicity of talc and granite dust as estimated from an in vivo hamster bioassay. Toxicol Appl Pharmacol 1987; 87:222-34.

24 Begin R, Dufresne A, Cantin A, Possmayer F, Sebastien P. Quartz exposure, retention, and early silicosis in sheep. Exp Lung Res 1989;15:409-28.

25 Bruch J, Li C, Gono E, Song H. Differences in the retention and elimination after inhalation of a mineral poor and a mineral rich mine dust. In: Ergebnisse von Untersuchungen auf dem Gebiet der Staub-und Silikose-bekämpfung ing Steinkohlebergbau. Essen: 1987: 229-36.

$26 \mathrm{Li} \mathrm{C}$, Bruch J. Factors controlling particle elimination and penetration in the lung effect of particle properties International conference on inhalation toxicology: the design and interpretation of inhalation studies and their use in risk assess ment. Hanover, Germany, 23-27 March, 1987; 23-7.

27 Grünspan $M$, Antweiler $H$, Dehnen $W$. Effect of silica on phospholipids in the rat lung. $B r F$ Ind Med 1973;30:74-7.

28 Miller K, Webster I, Handfield R, Skikne MI. Ultrastructure of the lung in the rat following exposure to crocidolite asbestos and quartz. F Pathol 1978;124:39-44.

29 Rehn B, Gono E, Pison U, et al. Der Einfluß der Staubbelastung auf die Zusammensetzung des Surfactants. In: Norpoth K, ed. 27. Fahrestagung der Deutschen Gesellschaft für Arbeitsmedizin 1987. Stuttgart: 1987:531-4.

$30 \mathrm{Li} \mathrm{C}$, Bruch J, Pison U. Phospholipid lung profile in rats after different dust exposure. $A m$ Rev Respir Dis 1987;135:A 447.

31 Kawada H, Horiuchi T, Shannon JM, et al. Alveolar type II cells, surfactant protein A (SP-A), and the phospholipid components of surfactant in acute silicosis in the rat. $\mathrm{Am}$ Rev Respir Dis 1989;140:460-70.

32 Liau DF, Barret CR, Bell ALL, Ryan SF. Functional abnormalities of lung surfactant in experimental acute alveolar injury in the dog. Am Rev Respir Dis 1987;136:395-401.

33 Horiuchi T, Mason RJ, Kuroki Y, Cherniak M. Surface and tissue forces, surfactant protein $\mathrm{A}$, and the phospholipid components of pulmonary surfactant in bleomycin-induced pulmonary fibrosis in the rat. Am Rev Respir Dis 1990; 141:1006-13.

34 Klein B. Anderung des Lungensurfactants bei asbeststaubexponierten Patienten [dissertation] Essen: University of Essen. 1992.

35 Hallmann M, Spragg R, Harrel JM, Moser KM. Evidence of lung surfactant abnormality in respiratory failure. Study of bronchoalveolar lavage phospholipids, surface activity, and plasmamyoinositol. $\mathcal{f}$ Clin Invest 1982;70:673-83.

36 Robinson PC, Watters LC, King TE, Mason RJ. Idiopathic pulmonary fibrosis. Abnormalities in bronchoalveolar lavage fluid phospholipids. Am Rev Respir Dis 1988;137:585-91.

Accepted 19 October 1992 